\title{
Narrativas Populares para Transmissão de Valores em Jogos Sérios Baseados em Processos de Serviços Públicos para Cidadãos Brasileiros
}

\author{
Fabrício Janssen $^{1}$, Mariano Pimentel ${ }^{1}$, Renata Araujo ${ }^{2}$ \\ ${ }^{1}$ Programa de Pós-Graduação em Informática \\ Universidade Federal do Estado do Rio de Janeiro (PPGI - UNIRIO) \\ ${ }^{2}$ Faculdade de Computação e Informática - Universidade Presbiteriana Mackenzie \\ Laboratório de Ludologia, Engenharia e Simulação - COPPE/UFRJ \\ fabricio.janssen@uniriotec.br, pimentel@uniriotec.br \\ renata.araujo@mackenzie.br
}

Abstract. Brazil is a low schooling country which consumes in large scale: games, cell phones and television. In this context, promoting citizen awareness and participation has been a challenge. Research areas study the potential of serious digital games for this purpose. Previous research has proposed the Play Your Process (PYP), a method of designing serious games based on public service processes aimed at promoting citizens' understanding of how these services work. One of the challenges of building games based on PYP is how to convey values through them. This dissertation aims to evolve the PYP proposing the use of techniques of popular narratives to integrate values.

Resumo. O Brasil é um país de baixa escolaridade e que consome em larga escala: jogos, celulares e televisão. Nesse contexto, promover a conscientização e participação cidadã da população tem sido um desafio. Áreas de pesquisa estudam o potencial de jogos digitais sérios para este fim. Pesquisas anteriores propuseram o Play Your Process (PYP), um método de design de jogos sérios baseados em processos de serviços públicos com objetivo de promover o entendimento dos cidadãos sobre o funcionamento destes serviços. Um dos desafios da construção de jogos com base no PYP é como transmitir valores por meio deles. Essa dissertação objetiva evoluir o PYP propondo para o design o uso de técnicas de narrativas populares para integrar valores.

\section{Introdução}

No Brasil e no mundo, diversas iniciativas têm surgido para promover sociedades mais democráticas. Devido ao maior acesso pelos cidadãos à Internet, muitas dessas iniciativas se dão no meio digital. Em se tratando das organizações públicas, a aproximação desses atores, cidadãos, e das instituições, é um grande desafio ${ }^{1}$.

\footnotetext{
${ }^{1}$ CGI.BR. https://www.cetic.br/media/docs/publicacoes/2/TIC eGOV 2017 livro eletronico.pdf
} 
Entender como um processo de prestação de serviço funciona pode ser uma tarefa bastante complexa para o cidadão, principalmente em um país de baixa escolaridade, o que amplifica o desafio. De acordo com o IBGE (Instituto Brasileiro de Geografia e Estatística), mais da metade da população brasileira (51\%) com 25 anos ou mais tinham concluído apenas o ensino fundamental, segundo dados de 2016 do IBGE $^{2}$.

Neste contexto, o Grupo de Pesquisa e Inovação em Ciberdemocracia ${ }^{3}$ (CIBERDEM) vem realizando diversas pesquisas. Dentre elas, encontra-se a proposta de explorar o potencial de jogos digitais sérios como uma alternativa para promover o entendimento de processos de serviços públicos, que gerou o Play your Process (PYP) [Classe, Xexéo, Araujo e Siqueira 2018], um método cujo objetivo é sistematizar o design de jogos a partir de modelos de processos de serviços públicos.

\section{Apresentação do Problema}

Pesquisas anteriores nesse contexto levantaram uma preocupação com o fato de que um dos aspectos importantes para a eficácia dos jogos são os valores que eles transmitem [Classe, Xexéo, Araujo e Siqueira 2018]. A ideia de que valores podem ser incorporados em sistemas e dispositivos técnicos (artefatos) foram alvo de uma variedade de abordagens disciplinares para o estudo da tecnologia, sociedade e humanidade [Flanagan, Nassembaum e Howe 2005]. A escritora e game designer americana Mary Flanagan desenvolveu uma abordagem metodológica, chamada de Values at play (VAP), ou Valores no Jogo, que busca estudar alternativas para desenvolvimento de jogos que possam agregar valores positivos para quem os joga. No entanto, se integrar valores em jogos sérios já é um desafio, ele se torna maior para os jogos baseados em processos de serviços públicos, sobretudo no Brasil.

Um dos elementos mais importantes de um jogo e que vem ganhando cada vez mais importância nas últimas décadas é a narrativa. Ela é um fator relevante para o envolvimento emocional do jogador, a qual permite um melhor aproveitamento de seus objetivos transmitidos, que não visam apenas o entretenimento [Despain 2012]. A utilização de técnicas, métodos e/ou padrões podem auxiliar na eficácia da narrativa relacionada aos objetivos gerais do jogo sério, incluindo seus valores. Porém, sua aplicação pode ser considerada um processo um tanto complexo. A utilização de técnicas, métodos e/ou padrões podem auxiliar na eficácia da narrativa relacionada aos objetivos gerais do jogo sério, o que nos leva à seguinte questão de pesquisa (QP): Como realizar o design de valores por meio de narrativas em jogos sérios digitais baseados em processos de prestação de serviços públicos, de forma sistematizada?

\section{Proposta de Solução}

A ideia dessa pesquisa é definir um método para integrar valores utilizando técnicas de narrativas e garantir que os jogos criados possam mudar a visão do cidadão brasileiro sobre os serviços. Também espera-se que esses jogos sejam prazerosos e lúdicos.

\footnotetext{
${ }^{2}$ Agência IBGE: https://agenciadenoticias.ibge.gov.br/agencia-sala-de-imprensa/

${ }^{3}$ CiberDem: http://ciberdem.uniriotec.br/
} 
Para desenvolvimento da proposta foi escolhida a metodologia Design Science Research (DSR) [Pimentel, Filippo e Santoro 2018]. Para a construção do artefato, foram previstos dois ciclos. No primeiro, está sendo criada uma versão preliminar do método integrando técnicas de narrativas conhecidas na literatura ao método $P Y P$. Além do PYP, as ferramentas Final Draft ${ }^{4}$ e Construct $2^{5}$ compõem a base técnica dessa etapa. $\mathrm{Na}$ base teórica, estão sendo utilizados conceitos de ciberdemocracia e de técnicas de narrativas.

No segundo ciclo, o método será evoluído com base nos resultados obtidos ao final do primeiro ciclo. Serão integradas à base teórica, as técnicas de narrativas utilizadas pelas telenovelas brasileiras. E qual o porquê desta escolha específica? De acordo com levantamento da Kantar Ibope Media, o brasileiro assistiu a 6 horas e 23 minutos de televisão por dia em 2017. O gênero telenovela foi o mais consumido ${ }^{6}$. A telenovela é de extrema importância para o Brasil, servindo como uma verdadeira "vitrine cultural" [Pallottini 2012]. Suas técnicas de narrativa, por serem comprovadamente populares, serão estudadas e incorporadas a esse estudo. A metodologia VAP também será integrada neste ciclo.

O método que será criado ao final dessa pesquisa, portanto, será uma combinação de PYP com técnicas de narrativas populares e o método VAP.

\section{Avaliação dos Resultados}

Ao final do primeiro ciclo, espera-se ter a primeira versão do método e um jogo produzido a partir de sua integração com o PYP, verificando a capacidade do método de construir narrativas para os jogos projetados pelo PYP, gerando jogos válidos. Ao final do segundo ciclo, o jogo será avaliado por usuários, quanto a seus aspectos inerentes a este tipo de produto (jogabilidade, satisfação, diversão, etc), mas com foco em verificar se os valores integrados na narrativa são percebidos.

\section{Atividades já realizadas}

Foi realizada a revisão bibliográfica e o mapeamento sistemático da literatura (MSL), com foco em estudos sobre o uso de narrativas para transmitir valores em jogos. Foram levantados 16 de um total de 428 artigos pesquisados nas principais bases científicas, como IEEE Xplore e Scopus. Observou-se que há poucas pesquisas e que existem diversas formas de abordagem no contexto de jogos sérios. Além disso, todos os estudos encontrados foram de fora do Brasil.

Com o objetivo de compreender o contexto acadêmico da utilização de narrativa em jogos sérios, foi realizado um survey com 26 pesquisadores e atuantes brasileiros nessa área. Todos os respondentes consideraram importante o uso de narrativa e apenas um mostrou-se indiferente quanto à importância de se abordar valores.

\footnotetext{
${ }^{4}$ Final Draft https://www.finaldraft.com/

${ }^{5}$ Construct 2. https://www.scirra.com/construct2

${ }^{6}$ Ibope. https://www.kantaribopemedia.com
} 
Também foi realizada uma análise dos valores transmitidos no jogo Prosperópolis, baseado no processo de concessão do Programa Bolsa Família (PBF). Foram escolhidos 5 valores (inclusão, justiça, cidadania, dignidade e confiabilidade) e verificado se estes foram identificados por 6 jogadores após 30 minutos de jogo Observamos que mesmo sem terem sido pensados de forma sistematizada, quase todos os valores foram percebidos [Janssen, Antonio, Xavier, Araujo e Fornazin 2018].

\section{Conclusão}

A Sociedade Brasileira de Computação (SBC) tem se preocupado em prospectar os principais desafios de pesquisa na área de Sistemas de Informação (SI). Um deles é "SI e o Mundo Aberto", que tem "Metodologias e tecnologias para participação popular" como um dos subtemas [Araujo, Maciel e Boscarioli 2017]. Acredita-se que esta pesquisa tem o potencial de contribuir para os desafios da área, por abordar a construção de SIs para o mundo aberto e para a participação popular.

Contribui, em particular, para as áreas científicas de ciberdemocracia e jogos digitais pela proposição de um método para construção de narrativas em jogos visando a integração de valores no cenário brasileiro no contexto de serviços públicos.

A pesquisa também tem o potencial de contribuir para a indústria de design de jogos nacional, principalmente à área de design, com a proposição de um método que trabalhe narrativas brasileiras populares em jogos digitais. Cabe destacar que nos últimos dois anos, 1718 jogos foram produzidos no Brasil, sendo $43 \%$ deles para dispositivos móveis e 874 classificados como jogos sérios ${ }^{7}$.

\section{Referências}

Araujo, R.M., Maciel, R.S. and Boscarioli, C. (2017) "I GranDSI-BR: Grandes Desafios de Pesquisa em Sistemas de Informação no Brasil (2016-2026)"

Classe, T., Xexeo, G., Araujo, R.M. and Siqueira, S. (2018) "PYP - Play Your Process: Um Método de Design de Jogos Digitais Baseados em Processos de Negócio".

Despain, W. (2012). “100 principles of game design”. New Riders Publishing.

Flanagan, M., Nissembaum, H. and Howe, D. (2005). "Embodying Values in

Technology: Theory and Practice New York University"

Janssen, F., Antonio, N., Xavier, B., Araujo, R.M. and Fornazin, M., (2018) “Jogo PBF:

Design de valores em um jogo digital sobre o Programa Bolsa Família”

Pallottini, R. (2012). Dramaturgia de televisão. 2. ed. São Paulo: Boitempo.

Pimentel, M., Filippo, D. and Santoro, F., (2018). “Design Science Research:

fazendo pesquisas científicas rigorosas atreladas ao desenvolvimento de artefatos computacionais projetados para a educação".

\footnotetext{
${ }^{7}$ Mercado de Games vem crescendo em todo o Brasil. https://canaltech.com.br/games/
} 